\title{
Comment on: use of blood biomarkers to screen for obstructive sleep apnea
}

\section{Burton Abrams}

Zeger-Abrams Inc., Elkins Park, PA, USA
Correspondence: Burton Abrams 22I Linden Drive, Elkins Park, PA 19027, USA

Email burtabrams@hotmail.com
This article was published in the following Dove Press journal: Nature and Science of Sleep

\section{Dear editor}

The recently published paper in Nature and Science of Sleep ${ }^{1}$ describes a combination of blood biomarkers for obstructive sleep apnea (OSA) screening which is shown to have better sensitivity and selectivity than any one individually. The combination comprises elevated levels of glycated hemoglobin (HbA1c), C-reactive protein, and erythropoeitin. The combination algorithm alluded to in the paper requires a sufficiently elevated level above a threshold of the combination of the three constituents for further diagnostic testing to be recommended. Of course, OSA would have to have been present long enough for the elevated levels to occur in order for the proposed biomarker to indicate its likely presence. My comment on this paper questions not whether this screening tool is valid, but whether it is valid early enough in the development of OSA to initiate diagnosis and treatment before some irreversible life-threatening consequence of OSA develops.

In particular, I focus on $\mathrm{HbAlc}$, which when elevated above $5.7 \%$ indicates prediabetes or diabetes, a recognized common consequence of OSA which risks the quality and length of life. The meta-analyses in $^{2,3}$ conclude that overcoming OSA does not generally reduce $\mathrm{HbAlc}$, although it may improve insulin sensitivity. Insulin insufficiency from beta cell dysfunction and mass reduction remains to keep $\mathrm{HbAlc}$ elevated, and diabetes is still a threat.

There is another biomarker, although not a blood biomarker, which appears earlier in the development of OSA. It is the formation of monosodium urate crystals on patellar, biceps, or quadriceps tendons, where they are detectable by ultrasonic means. ${ }^{4}$ The intermittent hypoxemia which results from OSA causes three effects which quickly elevate the concentration of serum uric acid, often leading to the precipitation of monosodium urate crystals: 1) intermittent cell catabolism which culminates irreversibly in the generation of excess uric acid fed into the blood; 2) concurrent intermittent serum acidosis and hypercapnia which reduces the solubility of uric acid in the blood; and 3) gradual reduction of the kidneys' glomerular filtration rate which slows removal of serum uric acid. Once formed, the crystals dissolve very slowly, which allows for their detection at any time convenient for OSA screening. 


\section{Disclosure}

The author reports no conflicts of interest in this communication.

\section{References}

1. Fleming WE, Holty JC, Bogan RK, et al. Use of blood biomarkers to screen for obstructive sleep apnea. Nat Sci Sleep. 2018;10:159-167.
2. Feng Y, Zhang Z, Dong ZZ. Effects of continuous positive airway pressure therapy on glycaemic control, insulin sensitivity and body mass index in patients with obstructive sleep apnoea and type 2 diabetes: a systematic review and meta-analysis. NPJ Prim Care Respir Med. 2015;25:15005.

3. Labarca G, Reyes T, Jorquera J, et al. CPAP in patients with obstructive sleep apnea and type 2 diabetes mellitus: systematic review and metaanalysis. Clin Respir J. 2018. In press.

4. Abrams B. Monosodium urate as a biomarker for obstructive sleep apnea. J Sleep Disord: Treat Care. 2017;6(2). 


\section{Authors' reply \\ Wesley Elon Fleming' \\ Jon-Erik C Holty ${ }^{2}$ \\ Richard K Bogan ${ }^{3}$ \\ Dennis Hwang ${ }^{4}$ \\ Aliya S Ferouz-Colborn ${ }^{4}$ \\ Rohit Budhiraja ${ }^{5}$ \\ Susan Redline ${ }^{5}$ \\ Edith Mensah-Osman ${ }^{6}$ \\ Nadir Ishag Osman ${ }^{6}$ \\ Qing $\mathrm{Li}^{7}$ \\ Armaghan Azad' \\ Susann Podolak' \\ Michael K Samoszuk ${ }^{8}$ \\ Amabelle B Cruz ${ }^{8}$ \\ Yang $\mathrm{Bai}^{8}$ \\ Jiuliu Lu ${ }^{8}$ \\ John S Riley ${ }^{8}$ \\ Paula C Southwick ${ }^{8}$ \\ 'Sleep Center Orange County, Irvine, CA, USA; ${ }^{2}$ Stanford Medical School, VA Palo Alto Health Care System, Pulmonary, Critical Care and Sleep Medicine Section, Palo Alto, CA, USA; ${ }^{3}$ SleepMed Inc., Bogan Sleep Consultants, LLC, Columbia, SC, USA; ${ }^{4}$ Sleep Medicine Department, Southern California Permanente Medical Group, Kaiser Permanente, Fontana Medical Center, Fontana, CA, USA; ${ }^{5}$ Division of Sleep Medicine, Harvard Medical School, Brigham and Women's Hospital, Boston, MA, USA; ${ }^{6}$ EENA Comprehensive Neurology and Sleep Center, Boynton Beach, FL, USA; ' $5 o u$ th Bend Medical Foundation, New Technology and Test Development, South Bend, IN, USA; ${ }^{8}$ Clinical Research Department, Beckman Coulter, Inc., Brea, CA, USA}

Correspondence: Wesley Elon Fleming

Sleep Center Orange County, 4980 Barranca Pkwy, Ste 170, Irvine, CA 92604, USA

$\mathrm{Tel}+\mathrm{I} 9496795510$

Fax + I 9496791080

Email flemingwesley@gmail.com

\section{Dear editor}

We would like to thank Burton Abrams, MS, for the letter in response to our recently published article.

$\mathrm{Mr}$ Abrams questions whether our new screening tool is valid early enough in the development of OSA to initiate diagnosis and treatment before irreversible life-threatening consequences of OSA develop. We would like to reiterate that the algorithm score derived from a combination of three biomarkers correlated with severity of disease (none, mild, moderate, severe), allowing sleep centers to identify and triage lower- to higher-risk patients for sleep study testing and treatment. In addition, the combination of biomarkers performed significantly better than current screening methods. Given that up to $90 \%$ of individuals with obstructive sleep apnea (OSA) remain undiagnosed and untreated, this new screening tool represents a substantial improvement in early identification of OSA.

Mr Abrams' work on ultrasonic detection of monosodium urate is interesting, and we commend any effort to improve upon the early detection of OSA.

\section{Acknowledgment}

This work was supported by research grant funding from Beckman Coulter, Inc. (Brea, CA, USA) provided to the respective institutions of Drs Fleming, Holty, Bogan, Hwang, Ferouz-Colborn, Budhiraja, Redline, Mensah-Osman, Osman, and Li.

\section{Disclosure}

Drs Samoszuk, Riley, and Southwick, as well as Ms Cruz, Mr Bai, and Mr Lu are employed by Beckman Coulter. The authors report no other conflicts of interest in this communication.

Dove Medical Press encourages responsible, free and frank academic debate. The content of the Nature and Science of Sleep 'letters to the editor' section does not necessarily represent the views of Dove Medical Press, its officers, agents, employees, related entities or the Nature and Science of Sleep editors. While all reasonable steps have been taken to confirm the content of each letter, Dove Medical Press accepts no liability in respect of the content of any letter, nor is it responsible for the content and accuracy of any letter to the editor.

\section{Publish your work in this journal}

Nature and Science of Sleep is an international, peer-reviewed, open access journal covering all aspects of sleep science and sleep medicine, including the neurophysiology and functions of sleep, the genetics of sleep, sleep and society, biological rhythms, dreaming, sleep disorders and therapy, and strategies to optimize healthy sleep. The manuscript

\section{Dovepress}

management system is completely online and includes a very quick and fair peer-review system, which is all easy to use. Visit http://www. dovepress.com/testimonials.php to read real quotes from published authors. 